\title{
Measurements behind Internal Insulation on Solid Masonry Walls with Different Orientations and Degrees of Repair in a Danish Multi-story Building
}

\author{
Lies Vanhoutteghem ${ }^{1, *}$, Britt Haker Høegh ${ }^{1}$, and Thor Hansen ${ }^{1}$ \\ ${ }^{1}$ Danish Technological Institute, Department of Building and Construction, Gregersensvej, 2630 Taastrup, Denmark
}

\begin{abstract}
Internal insulation is used in many heritage buildings to ensure a better indoor environment and reduce energy use. This article describes measurement results from installing an internal insulation system in a Danish multi-story building. The internal insulation system consists of a fully glued vapour tight insulated plasterboard. To reduce the risk for wood decay and mould growth at the wooden beam ends in the floor construction, a 100-200 mm uninsulated gap was left above and below the floor construction. Measurements include the effect of orientation, degree of façade repair and influence of indoor moisture content. Results show in general acceptable hygrothermal conditions behind the insulation system. However, a gradual increase in relative humidity at sun-exposed walls was registered due to 'summer condensation'. The degree of surface repair also showed an influence on relative humidity levels during this period. At the uninsulated gap above the floor, a higher moisture content indoor resulted in a higher relative humidity, though without exceeding the threshold for mould growth. However, a large temperature range was registered. The influence of the uninsulated gap on reducing the risk of wood decay and mould growth at the beam ends could therefore not unambiguously be confirmed.
\end{abstract}

\section{Introduction}

Internal insulation is often the only suitable measure to reduce the energy use and ensure a better indoor climate in heritage buildings, or buildings worthy of preservation. However, several risks relate to the application of internal insulation, as the hygrothermal conditions in the existing walls change. Applying internal insulation reduces the inside temperatures and the drying potential of the original walls, which not only increases the risk for interstitial condensation [1], but also risk of mould growth and wood decay at the embedded beam ends. Furthermore, the risk of frost damage of the wall surface is increased [2].

The choice of insulation system, and its effect on hygrothermal behaviour of the walls and beam ends is subject to much research, as systems for internal insulation or continuously evolving [3-8].

Besides the choice of insulation system, the performance of the existing façade, and the influence of wind driven rain have a large impact on the hygrothermal behaviour of the walls [9]. Hence, several studies investigated the effect of façade impregnation and hydrophobation [10-12]. In this paper, influence of façade repair is instead considered.

To reduce the risk for mould growth and wood decay at the beam ends, one suggestion is to avoid air exfiltration, as well as air circulation near the beam ends, in cases where no wind-driven rain is present [13]. Others found out that leaving a $200 \mathrm{~mm}$ uninsulated gap above and below the embedded wooden beams reduced the risk of mould growth at the beam ends $[12,14]$. However, this depended on the orientation and the thickness of the existing wall.

This knowledge was used in the ARIE project ("Anvendeligheden og robustheden af indvendig efterisolering', in Danish), where DTI (Danish Technological Institute) was involved with investigating the performance of different internal insulation systems, with regards to their buildability (design) and robustness. Results in this paper describe the design and measurement data from an internal insulation system in one of the projects case buildings.

\section{Description of case building}

The case building at Ryesgade 25 in Copenhagen is a 5 storey apartment building from 1906, worthy of preservation, with solid masonry walls. Thickness of the masonry wall varied between $48 \mathrm{~cm}\left(1^{\text {st }}\right.$ to $3^{\text {rd }}$ floor $)$ and

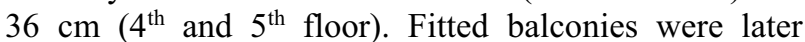
installed, with supporting profiles protruding $36 \mathrm{~cm}$ in the masonry.

The entire building was undergoing a complete renovation, including a modification of the layout of the apartments, application of internal insulation, and establishment of mechanical ventilation in all apartments.

At the same time, the facades of the building were repaired differently. The façade to the northeast was hot water washed and newly grouted, the facade to the southeast and part of the southwest facing facade were

\footnotetext{
${ }^{*}$ Corresponding author: liva@,teknologisk.dk
} 
cleaned with a low pressure wet blast and newly grouted, and on the remaining part of the facade to the southwest, the joints were partially repaired/newly grouted where needed, without further cleaning, see also Fig 1.

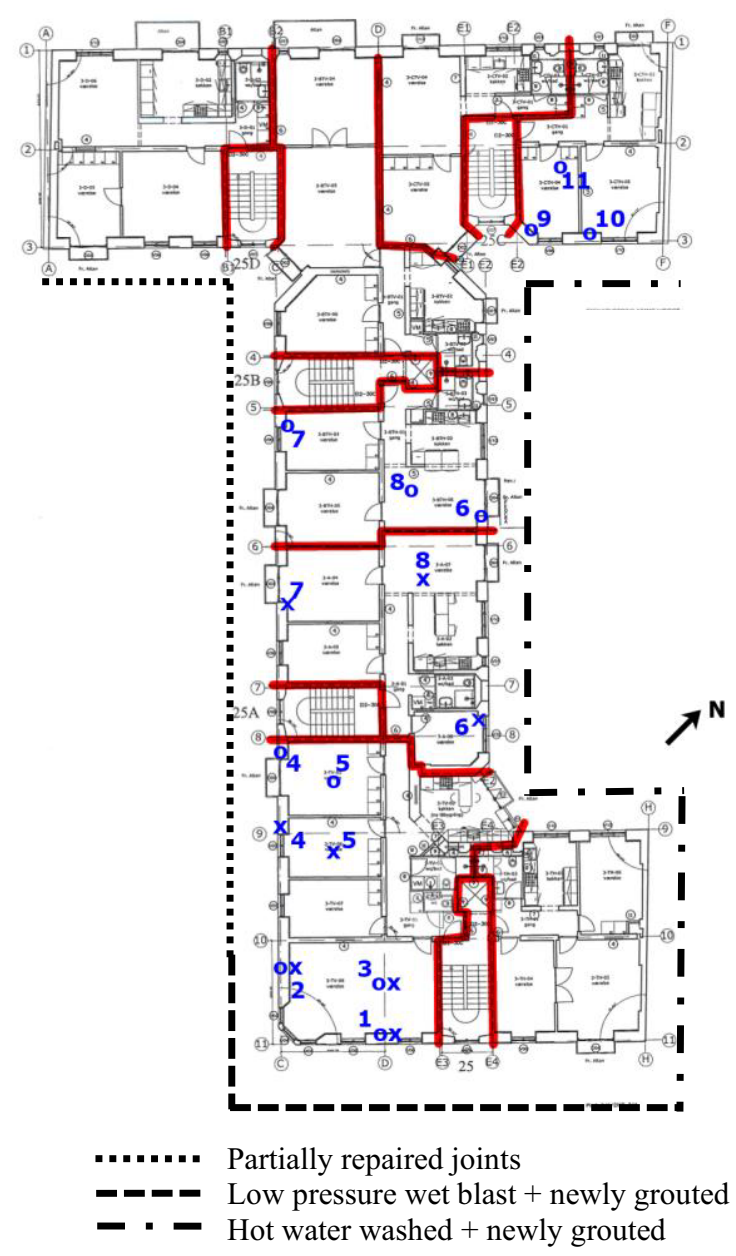

Fig. 1. Floor plan of apartments for the $3^{\text {rd }}$ and 4 th floor. Sensor locations on the $3^{\text {rd }}$ floor are indicated by circles, sensor locations on the $4^{\text {th }}$ floor are indicated by crosses.

\subsection{Insulation system}

When planning the internal insulation, solution details were considered to meet certain practical and building physical challenges. In the end, Kingspan Kooltherm K118 was chosen, which is a vapour tight system and at the time of installation consisted of a plasterboard with $50 \mathrm{~mm}$ phenolic core and a vapour barrier (aluminium foil) between the plasterboard and insulation. The system was fully glued to the existing walls and applied with only vertical joints between the insulation boards. Before installation of the system, the interior surface of the existing walls was cleaned for all organic material, e.g. wallpaper and paint, and the rendering was repaired where necessary.

To reduce the risk for wood decay and mould growth at the wooden beam ends in the floor construction, a 100-200mm uninsulated gap was left respectively above and below the floor construction, resulting in a cavity between the skirting and finished ceiling/stucco see Fig. 2. This creates an intentional thermal bridge in order to increase the temperature and drying potential at the wooden beam ends. Furthermore, no insulation was applied between the beams in the floor construction.

A planned vapour barrier in the cavity behind the skirtings and stucco (dotted line in Fig. 1) was later omitted, as it would be technically too difficult to establish this vapour barrier without any leakage points. Instead, the cavity behind the skirtings and stucco is to a certain extent ventilated with indoor air, through e.g. cracks and openings for electrical installations.

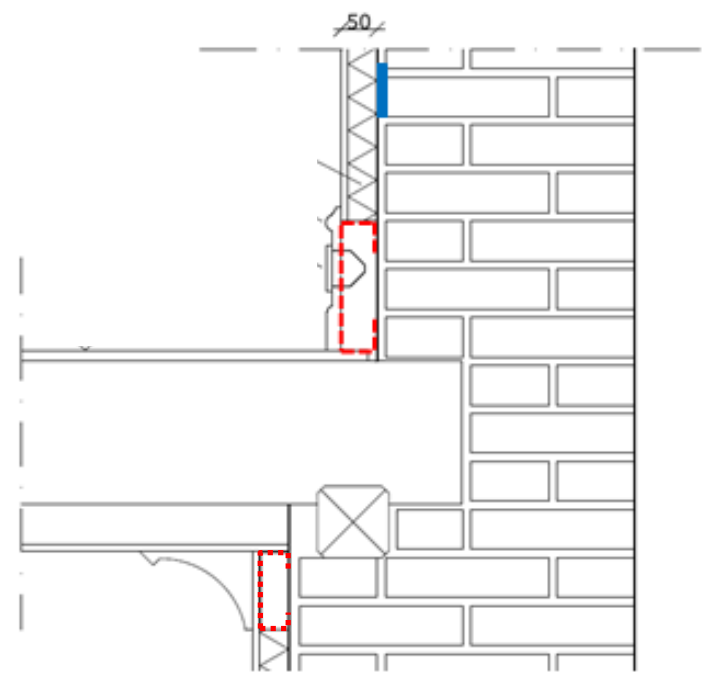

Fig. 2. Detail of the insulation system fully glued to the outer wall. The dotted line indicates the planned location of the vapour barrier, which was not established. The bold mark indicates the measurement position of the sensor $0,5 \mathrm{~m}$ above the floor, placed in a recess in the masonry.

\subsection{Measurement set up}

Sensors of the type Rotronic - HygroClip2 $( \pm 0.8 \% \mathrm{RH}$, $\pm 0.1{ }^{\circ} \mathrm{C}$ ) have been used to record hourly values for temperature and relative humidity at the interface between the existing walls and the internal insulation from June 5, 2017 to November 6, 2018.

Sensors were installed in a total of 5 different apartments, 3 on the $3^{\text {rd }}$ floor and 2 on the $4^{\text {th }}$ floor. The apartments were selected to include the effect sunexposure at different orientations, and different degrees of façade repair at these orientations. Sensor locations in the different apartments are shown in Fig 1.

\subsubsection{Measurement positions}

Sensor locations at the wall-insulation interface, as indicated on Fig. 1 include measurements at 3 different heights: behind the skirting, ca. $0,5 \mathrm{~m}$ above the skirting and ca. 1,1 $\mathrm{m}$ above the skirting (middle of the wall). In addition to measurements on the walls, indoor temperature and relative humidity were measured in selected rooms. Outside climate data was used from a sensor located at the DTI in Taastrup (approx. $20 \mathrm{~km}$ from the case building). Table 1 indicates the measurement positions and sensor name for the sensors at each measurement location. 
Table 1. Location of sensors on $3^{\text {rd }}$ and $4^{\text {th }}$ floor. Numbers indicate sensor name RTXX.

\begin{tabular}{|c|c|c|c|c|c|c|c|c|c|c|c|c|c|c|c|c|c|c|c|}
\hline \multirow[b]{3}{*}{$\begin{array}{l}\text { Measurement } \\
\text { location }\end{array}$} & \multicolumn{11}{|c|}{$3^{\text {rd }}$ floor } & \multicolumn{8}{|c|}{$4^{\text {th }}$ floor } \\
\hline & \multicolumn{5}{|c|}{$25-$ left (tv) } & \multicolumn{3}{|c|}{$25 \mathrm{~B}$ - right (th) } & \multicolumn{3}{|c|}{$25 \mathrm{C}-$ right (th) } & \multicolumn{5}{|c|}{$25-$ left (tv) } & \multicolumn{3}{|c|}{$25 \mathrm{~A}$} \\
\hline & 1 & 2 & 3 & 4 & 5 & 6 & 7 & 8 & 9 & 10 & 11 & 1 & 2 & 3 & 4 & 5 & 6 & 7 & 8 \\
\hline Room measurement & - & - & $\begin{array}{l}\text { RT } \\
61\end{array}$ & - & $\begin{array}{l}\text { RT } \\
64\end{array}$ & - & - & $\begin{array}{l}\text { RT } \\
67\end{array}$ & - & - & $\begin{array}{l}\text { RT } \\
69\end{array}$ & - & - & $\begin{array}{l}\text { RT } \\
72\end{array}$ & - & $\begin{array}{l}\text { RT } \\
75\end{array}$ & - & - & $\begin{array}{l}\text { RT } \\
76\end{array}$ \\
\hline Behind skirting & $\begin{array}{l}\text { RT } \\
73\end{array}$ & $\begin{array}{l}\text { RT } \\
65\end{array}$ & - & $\begin{array}{l}\text { RT } \\
74\end{array}$ & - & $\begin{array}{l}\text { RT } \\
66\end{array}$ & $\begin{array}{l}\text { RT } \\
79\end{array}$ & - & $\begin{array}{l}\text { RT } \\
77\end{array}$ & $\begin{array}{l}\text { RT } \\
78\end{array}$ & - & - & $\begin{array}{l}\text { RT } \\
62\end{array}$ & - & $\begin{array}{l}\text { RT } \\
63\end{array}$ & - & $\begin{array}{l}\text { RT } \\
68\end{array}$ & $\begin{array}{l}\text { RT } \\
70\end{array}$ & \\
\hline At height $500 \mathrm{~mm}$ & $\begin{array}{l}\text { RT } \\
51\end{array}$ & - & - & - & - & - & $\begin{array}{l}\text { RT } \\
60\end{array}$ & - & $\begin{array}{l}\text { RT } \\
57\end{array}$ & $\begin{array}{l}\text { RT } \\
54\end{array}$ & - & - & $\begin{array}{l}\text { RT } \\
49\end{array}$ & - & $\begin{array}{l}\text { RT } \\
48\end{array}$ & - & - & - & - \\
\hline At height $1100 \mathrm{~mm}$ & $\begin{array}{l}\text { RT } \\
50\end{array}$ & $\begin{array}{l}\text { RT } \\
53\end{array}$ & - & $\begin{array}{l}R T \\
52\end{array}$ & - & $\begin{array}{l}\text { RT } \\
46\end{array}$ & $\begin{array}{l}R T \\
55\end{array}$ & - & $\begin{array}{l}\text { RT } \\
59\end{array}$ & $\begin{array}{l}\text { RT } \\
47\end{array}$ & - & $\begin{array}{l}\text { RT } \\
43\end{array}$ & $\begin{array}{l}\mathrm{RT} \\
44\end{array}$ & - & $\begin{array}{l}\text { RT } \\
45\end{array}$ & - & $\begin{array}{l}\mathrm{RT} \\
56\end{array}$ & $\begin{array}{l}R T \\
58\end{array}$ & - \\
\hline
\end{tabular}

Italic numbers: Measurement data not available due to failure.

\section{Results}

To assess the hygrothermal performance of the internal insulation system, results have been compared to the critical moisture level for mould growth [15]. The critical moisture level can normally be set to $75 \% \mathrm{RH}$ at $20^{\circ} \mathrm{C}$ on organic surfaces, or surfaces that may be soiled or dust coated. The latter is also expected to be the case for interior surfaces in homes and is therefore used further on.

To smooth daily fluctuations, a weekly running average of measured data is used. Moreover, from the hourly measured values, the absolute water content, i.e. the amount of water vapour in $\mathrm{g} / \mathrm{m}^{3}$ was calculated [15]. To investigate the influence of varying moisture load on the performance of the internal insulation in different apartments, their moisture load was calculated based on the difference between the amount of water vapour in the indoor air and the outdoor air, see Fig. 3.



Fig. 3. Moisture load in the various apartments, as a difference between the water vapour content in the indoor and outdoor air.

The apartments were then assigned a humidity class (HC) [16], depending on the size of their indoor moisture content. Except for apartments 25-left on the $3^{\text {rd }}$ floor and 25-left on the $4^{\text {th }}$ floor, all apartments had a maximum indoor moisture load around $2 \mathrm{~g} / \mathrm{m}^{3}$ during winter (December to March), classifying them as HC 1, which is slightly drier than expected. However, this can be explained due to the installation of mechanical ventilation [17].
The moisture load in apartments 25 -left on the $3^{\text {rd }}$ floor and 25-left on the $4^{\text {th }}$ floor was classified as HC 2 , as the maximum indoor moisture load during winter (December to March) was around or just over $4 \mathrm{~g} / \mathrm{m}^{3}$.

\subsection{Conditions behind skirting}

Measured temperatures and relative humidity behind the skirtings are presented in Fig. 4. During the heating season, a large variation in measured relative humidity and temperature can be seen. The temperature behind the skirtings dropped in some cases to $5{ }^{\circ} \mathrm{C}$. However, in most cases, temperatures from mid-November to March lie between $10-18{ }^{\circ} \mathrm{C}$. For comparison, temperatures at the wall-insulation interface were between $5-10{ }^{\circ} \mathrm{C}$ in this period, i.e. temperatures behind the skirting were $5-8{ }^{\circ} \mathrm{C}$ higher than behind the insulated areas.

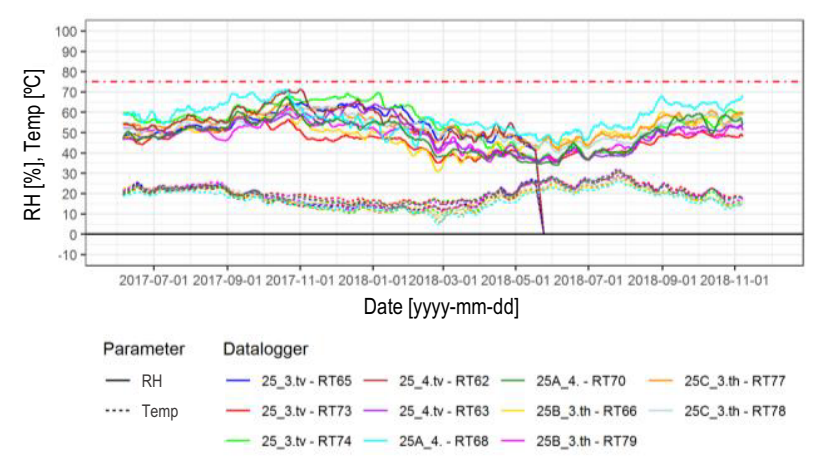

Fig. 4. Comparison of temperature and relative humidity measurements from sensors mounted behind the skirtings.

The relative humidity behind the skirtings never exceeded the critical relative humidity of $75 \%$, providing conditions for mould growth. Relative humidity was highest in October, with a slight decrease from October to November and a more pronounced decrease in January/ February. In the indoor climate, the decrease happens faster, i.e. there was some delay in achieving the equilibrium state in the cavity behind the skirtings.

The relative humidity behind the skirtings in winter was highest in the apartments with HC 2 (RT62, RT63, RT65 and RT74). 
To investigate the cause of the relatively large temperature variations behind the skirtings, the temperature difference between indoor air and skirtings was calculated, see Fig. 5. Calculated temperature differences in summer are between -6 and +3 degrees, while in winter (November to March) a difference between -14 and -3 degrees can be seen. Minimum and maximum spread in the temperature difference occurred in the month of June (ca. 3 degrees) and the month of February (ca. 12 degrees). No immediate correlation could be seen between the magnitude of the temperature difference and the orientation of the facade, as measurement points where the temperature difference was very large, are found both on sun-exposed (e.g. RT74, RT79) and shaded facades (e.g. RT68, RT77).

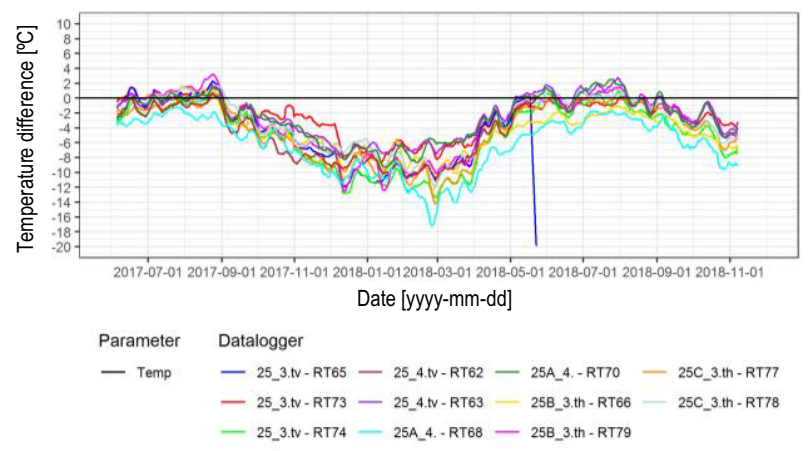

Fig. 5. Temperature difference between measurements behind the skirtings and indoor air temperature. Negative temperatures represent colder conditions behind the skirtings than in the indoor climate.

Three measurement points (RT74, RT66 on $3^{\text {rd }}$ floor and RT70 on $4^{\text {th }}$ floor) are located near balcony profiles in the facade. However, no clear correlation between the calculated temperature difference and location near balcony profiles could be found. The temperature difference at RT 74 on the 3rd floor, was very large, even though the balcony profile did not protrude all the way through the wall. In contrast, temperature differences at RT70 on the $4^{\text {th }}$ floor, where the balcony profiles do protrude all the way through the wall, do not differ from other measurements on the $4^{\text {th }}$ floor. The same can be seen for RT66 on the $3^{\text {rd }}$ floor.

\subsection{Conditions at wall-insulation interface}

Results from measurements showed a large deviation, both in measured temperatures and relative humidity at the wall-insulation interface, due to the influence of orientation. Therefore, measurement results are in the following presented separately for sun-exposed and shaded walls.

\subsubsection{Sun-exposed walls}

With regards to measured temperatures, a slight phase shift of approx. $1 / 2$ week can be seen between outdoor temperature and measured temperatures, see Fig. 6. No large temperature differences were registered between the different measurement points. This also applies for measurements at different heights at the wall-insulation interface However, large deviations in relative humidity, up to 40 percentage points, were registered from AprilJuly. In three of the measurement points (RT43, RT50 and RT51), the relative humidity in April and May rose above $75 \%$, but not above $85 \%$. These measuring points were located at southeast oriented facades. Of the other six functioning measuring points located in southwest oriented facades, five measurement points (RT44, RT45, RT48, RT49 and RT53) showed the same relative humidity levels in the beginning of April and then dropped steadily until approx. mid of July. The last meter (RT60) showed a fall already in March and reached the lowest relative humidity already in June, approx. two months prior to the other measuring points.
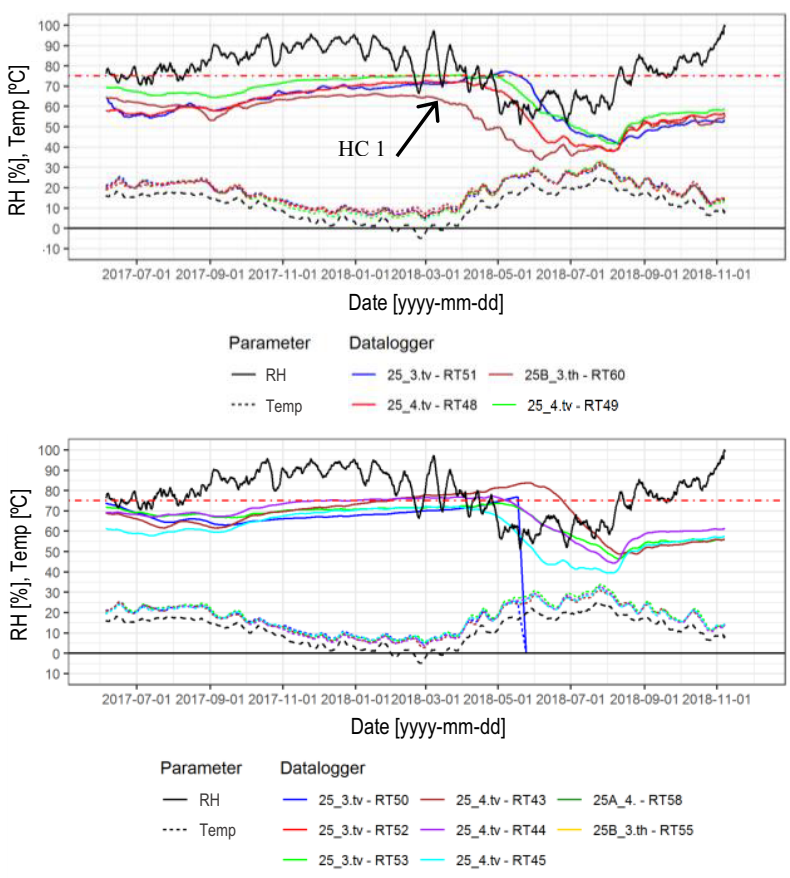

Fig. 6. Temperature and relative humidity at the wall-insulation interface for sun-exposed walls. Top: $0,5 \mathrm{~m}$ above the skirtings. Bottom: $1,1 \mathrm{~m}$ above the skirtings. Outdoor relative humidity and temperature are shown as black and dotted black curve respectively.

Eight of the nine functioning measurement points on the sun-exposed walls were in apartments with a moisture load HL 2. The last meter (RT60), which showed the lowest relative humidity levels, was in an apartment with HL 1. Six of the nine functioning measurement points (RT43, RT44, RT49, RT50, RT51 and RT53) were located on walls, whose facades had previously been cleaned with a low-pressure wet blast and were newly grouted. It is also at these measurement points where measured relative humidity in April/May is highest of all measurements. At walls with partially repaired joints, without further cleaning, relative humidity in two measurement points (RT48 and RT45) is higher than measurements points at shaded walls (see Fig. 7). Measurements from RT60, also at a wall with partially repaired joints and no further cleaning, show a relative humidity in line with measurements at shaded walls. 


\subsubsection{Shaded walls}

As for sun-exposed walls, a slight phase shift of approx. $1 / 2$ week could be seen between the outdoor temperature and measured temperatures at shaded walls, see Fig. 7.
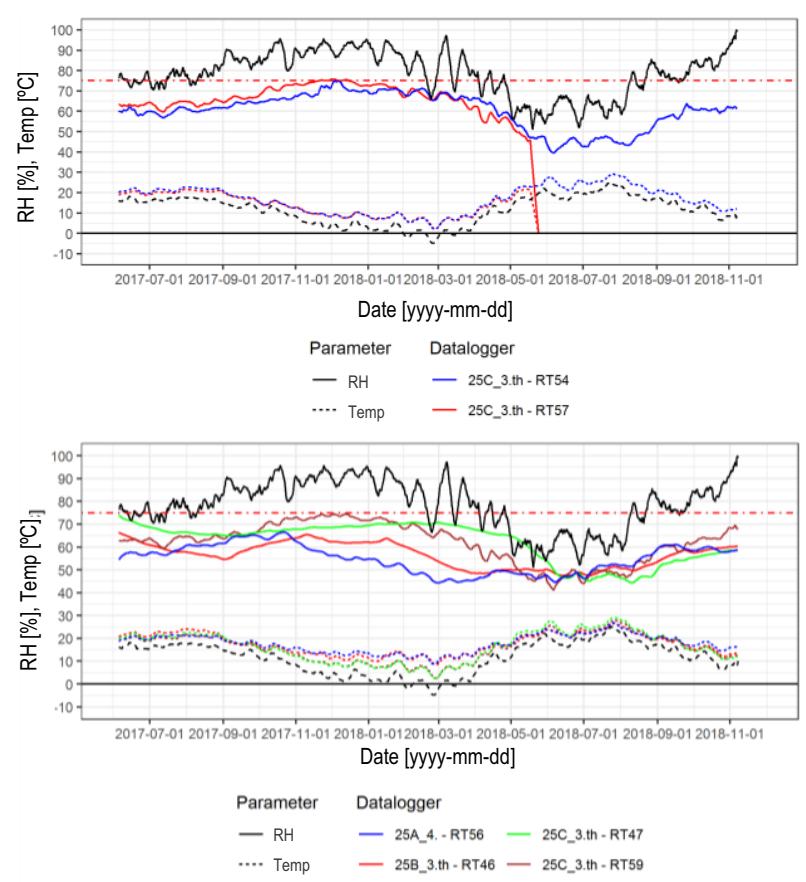

Fig.7. Temperature and relative humidity at the wall-insulation interface for shaded walls. Top: $0,5 \mathrm{~m}$ above the skirtings. Bottom: $1,1 \mathrm{~m}$ above the skirtings. Outdoor relative humidity and temperature are shown as black and dotted black curve respectively.

As for sun-exposed walls, no large deviations in temperature differences were registered between the different measurement points, except for RT46 and RT56. Contrary to the other measurement points for the shaded walls, these measurement points were not located at south-facing walls, but on a northeast facing wall. RT46 and RT56 at the northeast walls clearly recorded warmer temperatures in winter and colder temperatures in summer. Correspondingly, the relative humidity behind the insulation in winter was lower than for the other measurement points.

In none of the measurement points at shaded facades, an increase in relative humidity as for sun-exposed walls from March to June, was registered. Instead, relative humidity levels were lowest during summer, and highest during winter. In two measurement points (RT 57 and RT59), the relative humidity behind the insulation briefly reached the critical relative humidity. No correlation between indoor moisture load and measured relative humidity at the wall/insulation interface was found.

\section{Discussion}

An evaluation of the performance of the internal insulation is based on measurement data collected over a $1 \frac{1}{2}$ year period. For a long-term validation of the performance of the insulation system, a more extensive measurement period would be needed. However, some general trends could be observed during the $1 \frac{1}{2}$ year measurement period.

Measurements behind the skirtings showed temperatures that were 5-8 degrees higher than measurements at the wall-insulation interface. The masonry in the uninsulated areas behind the skirtings is thus warmer than the masonry behind the interior insulation, which shows some effect of intentionally creating a thermal bridge. However, measurements showed a large variation in temperatures, with periodically very low temperatures behind the skirtings. No correlation was found between the placement of the sensors near balcony profiles and the large temperature differences. The orientation of the facades also did not indicate to have an influence. It is estimated that the reason for the large temperature differences behind the skirtings may be related to random leaks in the facade or the extent to which the cavity behind the skirtings has been ventilated.

At the same time, measured relative humidity levels behind the skirtings did not exceed the critical humidity of $75 \%$ for mould growth. However, measured relative humidity levels were strongly influenced by the moisture load in the apartments. The higher the $\mathrm{HC}$ in the apartments, the higher the measured relative humidity behind the skirtings. If the concept of uninsulated areas behind the skirtings and at the finished ceiling is to be used, it is crucial to keep the moisture load in the apartments low. This can be challenged by inhabitants, turning of or blocking the ventilation system. Furthermore, due to the large variation in measured temperatures, measurements behind the skirtings cannot be used to document the hygrothermal conditions and reduced risk for mould growth at the beam ends without additional measurements at the beam ends.

At wall-insulation interfaces, the relative humidity in winter was considered most dependent on the temperature at the measurement point and not on the indoor moisture load. The phase shift between the outdoor temperature and measured temperatures at the wall-insulation interface was relatively short and is therefore also not considered to have a decisive influence on the measured relative humidity at the wall-insulation interface.

However, measurements at the wall-insulation interface showed a clear effect of orientation on the performance of the insulation system. The highest relative humidity levels (between $75-85 \%$ ) at the interface were measured during spring (April-June) for sun-exposed facades. During this period, an increase in outdoor temperature, combined with sunshine on the facade, created solar driven moisture transport towards the indoors, which increased the relative humidity levels at the wall-insulation interface. The phenomenon, called the 'summer condensation', subsided, after a new temperature equilibrium was reached in July. At shaded facades, this phenomenon was not registered, and generally, relative humidity levels were lower than at sun-exposed facades. 
Three measurement points on the south-east, and two measurement points on the southwest façade showed a relative humidity above $75 \%$, but below $85 \%$. Other sun-exposed measurements showed lower relative humidity levels and less distinctive influence of summer condensation. The above-mentioned measurement points at sun-exposed facades were in areas where the facades previously had been cleaned with a low-pressure wet blast, whereas other measurement points were located at facades that were partially repaired/newly grouted. Measurement results indicate therefore that this treatment of the facades may have contributed to an increased water uptake in the masonry, and hence higher relative humidity levels at the wall-insulation interface.

As the measured relative humidity levels at the wallinsulation interfaces were only above $75 \%$ relative humidity for shorter periods of time in single measurement series, and not above $85 \%$, and no organic materials are expected to be present behind the internal insulation, the risk for mould growth at the wallinsulation interface is considered to be minimal under the measured climate conditions. A colder winter, or a warmer and sunnier spring may possibly result in higher relative humidity levels at the wall-insulation interface.

Furthermore, a long-lasting full adhesion of the insulation to the wall and an indoor moisture load of $\mathrm{HC}$ 2 or below, is necessary for the robustness of the vapourtight insulation system. In this relation, it should be mentioned that vertical plate joints were not specially bonded or sealed for making them vapour tight. Furthermore, seasonal deformation of the insulation material will stress and possibly open the plate joints. This will increase the risk of hot humid indoor air penetrating these assemblies and causing local mould growth at the plate joints, especially at apartments with a high moisture load. Thus, measurements at the plate joints - in addition to monitoring at the wall-insulation interface behind whole plate areas - should be necessary to verify a long-term durability of the insulation system. It should be noted that the establishment of a mechanical ventilation system, at the same time of installing the internal insulation, is a measure to reduce the indoor moisture load, which will possibly minimise the risk of mould growth at plate joints. This requires though, that inhabitants do not turn of or block the ventilation system.

\section{Conclusion}

Measurements showed in general acceptable hygrothermal conditions with application of the chosen insulation system. However, a gradual increase in relative humidity at sun-exposed walls was registered due to 'summer condensation'. The length of this period with solar driven moisture transport towards the indoors varied at different sun-exposed locations. Furthermore, the degree of surface repair showed an influence on relative humidity levels during this period. A surface treatment with low pressure wet blasting resulted in the highest relative humidity levels between $75-85 \%$ in this period.
At walls without sun-exposure, no effect of 'summer condensation' was seen and the lowest relative humidity levels at the wall-insulation interface were registered. This in contrast with previous measurements [5] that showed that a lack of solar radiation yields little drying potential. However, it should be noted that the façade at these locations was hot water washed and all mortar joints were newly grouted, which influences the uptake of wind-driven rain (WDR).

At the wall-insulation interface, the influence of indoor moisture content on the relative humidity behind the insulation was found to be minimal. At the uninsulated gap above the floor, a higher moisture content indoor resulted in a higher relative humidity. However, the threshold for mould growth was not exceeded.

With regards to temperature, it is expected that leaving an uninsulated gap, and thereby creating an intentional thermal bridge, increases the temperature and drying potential at the wooden beam ends. Measurements in the uninsulated gap showed indeed higher temperatures than behind the insulation. However, a large temperature range was registered, with periodically very low temperatures. Additional measurements at the beam ends are needed to ensure acceptable hygrothermal conditions. Furthermore, documentation of long-term performance of the insulation system is needed, especially with regards to bonding of the system to the wall and influence of plate joints.

The authors would like to thank the ARIE project partners, Drost Fonden, Arup \& Hvidt advokater and rönby.dk ApS for their collaboration and support in the project.

\section{References}

1. E. Vereecken, L. Van Gelder, H. Janssen, S. Roels, Energ. Buildings 89 231-244 (2015)

2. X. Zhou, D. Derome, J. Carmeliet, Build. Environ. 125 285-298 (2017)

3. R. Walker, S. Pavia, Build. Environ. 94 155-162 (2015)

4. J. Zhao, J. Grunewald, U. Ruisinger, S. Feng, Build. Environ. 115 215-227 (2017)

5. T.K. Hansen, S. P. Bjarløv, R.H. Peuhkuri, M. Harrestrup, Energ. Buildings 172 235-248 (2018)

6. E. Vereecken, S. Roels, Int. J. Archit. Heritage $\mathbf{1 0}$ 558-569 (2016)

7. P. Johansson, S. Geving, C-E. Hagentoft, B:P. Jelle, E. Rognvik, A.S. Kalagasidis, B. Time, Build. Environ. 79 (2014) 31-45

8. T. De Mets, A. Tilmans, X. Loncour, En. Procedia. 132 (2017) 753-758

9. T.K. Hansen, S.P. Bjarløv, R. Peuhkuri, Energ. Buildings 196 255-268 (2019)

10. T.K. Hansen, S.P. Bjarløv, R. Peuhkuri, K. K. Hansen. Constr. Build. Mater. 188 695-708 (2018) 
11. G.R. Finken, S.P. Bjarløv, R.H. Peuhkuri, Constr. Build. Mater. 113 202-214 (2016)

12. T. Odgaard, S.P. Bjarløv, C. Rode, Energ. Buildings 173 530-546 (2018)

13. E. Vereecken, S. Roels, Build. Environ. 148 524534 (2019)

14. M. Harrestrup, S. Svendsen, Build. Environ, 99 5972 (2016)

15. E. Brandt, et al., SBi-guideline 224 - Moisture in buildings, $2^{\text {nd }}$ edition (In Danish). (Danish Building Research Institute, København SV, 2013)

16. ISO, ISO 13788:2012, Hygrothermal performance of building components and building elements Internal surface temperature to avoid critical surface humidity and interstitial condensation Calculation methods (2012)

17. M. Morelli, E.B Møller, Sci. Technol. Built. En. 25 7 1199-1211 (2019). 